\title{
LA STJUE DE 14 DE MAYO DE 2019, CCOO/ DEUTSCHE BANK (C-55/18), RELATIVA A LA OBLIGACIÓN DE LLEVAR UN REGISTRO DE LA JORNADA DIARIA DE TRABAJO Y LA APLICACIÓN HORIZONTAL DE OBLIGACIONES INSTRUMENTALES

\author{
MAGDALENA NOGUEIRA GUASTAVINO' \\ magnogua@hotmail.com
}

\section{Resumen}

La STJUE dictada en Gran Sala en el asunto C-55/18, sobre la obligación empresarial de llevar un registro de la jornada efectiva de cada uno de los trabajadores, resulta de extrema importancia, no solo por haber legitimado la reciente reforma normativa llevada a cabo por el Gobierno socialista, sino por contribuir a clarificar al-

Catedrática de Derecho del Trabajo de la Universidad Autónoma de Madrid. El presente comentario se enmarca en las actividades financiadas con el Proyecto de Investigación DER 2016-78646P (Programa estatal de fomento de la investigación científica del Ministerio de Ciencia, Innovación y Universidades. Proyectos de I+D-EXCELENCIA). 
gunas categorías jurídicas específicamente laborales manejadas por el TJUE, como la relativa a los principios y normas de Derecho social de «especial importancia» y, sobre todo, por ratificar la aplicación horizontal de los derechos de la Carta de Derechos Fundamentales de la Unión Europea desarrollados en su contenido por una directiva específica. El presente comentario examina, así pues, el contexto normativo y judicial español antes y después de las conclusiones del abogado general, poniendo de relieve la posición que después asumirá el propio Tribunal, las reacciones a la reforma normativa española y las cuestiones más relevantes extraíbles de la sentencia que legitima la obligación empresarial, esencial, aunque instrumental, de llevar un registro de jornada para garantizar la salud y seguridad de los trabajadores.

\title{
Palabras clave
}

Ordenación del tiempo de trabajo; directiva; derecho fundamental de los trabajadores a una duración máxima de la jornada de trabajo; obligación empresarial de registro del tiempo de trabajo.

THE ECJ JUDGEMENT OF MAY 14, 2019, CCOO/DEUTSCHE BANK (C-55/18), CONCERNING THE OBLIGATION TO CARRY OUT A WORKING DAY REGISTER AND THE HORIZONTAL APPLICATION OF INSTRUMENTAL OBLIGATIONS

\begin{abstract}
The STJUE issued in Grand Chamber in case C-55/18, on the employer's obligation to keep a record of the effective working hours of each of the workers, is extremely important, not only for having legitimized the recent reform carried out by the Socialist Government, but for helping to clarify certain specific labor legal categories handled by the ECJ, such as that relating to the principles and rules of social law of "special importance" and, above all, for ratifying the horizontal application of the rights of the Charter of Fundamental Rights of the European Union developed in their content by a specific directive. This commentary therefore examines the Spanish regulatory and judicial context before and after the conclusions of the Advocate General, highlighting the position that the Court will later assume, the reactions to the Spanish regulatory reform and the most relevant issues that can be extracted from the Judgment that legitimizes the essential, but instrumental, corporate obligation to keep a working day register in order to guarantee the health and safety of workers.
\end{abstract}

\section{Keywords}

Working Time Directive; Social fundamental right to a maximum duration of working time; employer's obligation to record working time. 


\section{L'ARRÊT DE LA CJUE DU 14 MAI 2019, CCOO/DEUTSCHE BANK (C-55/18), CONCERNANT L'OBLIGATION DE TENIR UN REGISTRE DU TEMPS DE TRAVAIL ET L'APPLICATION HORIZONTALE D'OBLIGATIONS INSTRUMENTALES}

\section{Résumé}

La STJUE rendue en grande chambre dans l'affaire C-55/18, relative à l'obligation de l'employeur de tenir un registre du temps de travail de chaque travailleur, est extrêmement importante, non seulement parce qu'elle a légitimé la récente réforme réglementaire menée par le gouvernement socialiste, mais aussi parce qu'elle a permis de clarifier certaines catégories spécifiques du droit du travail traitées par la CJUE, telles que celle relative aux principes et règles du droit social "particulièrement importants" et surtout, pour ratifier l'application horizontale des droits de la Charte des droits fondamentaux de l'Union européenne développés dans leur contenu par une directive particulière. Le présent commentaire examine donc le contexte réglementaire et judiciaire espagnol avant et après les conclusions de l'avocat général, en soulignant la position qui sera prise ultérieurement par la Cour elle-même, les réactions à la réforme réglementaire espagnole et les questions les plus pertinentes qui peuvent être tirées de l'arrêt qui légitime l'obligation essentielle, quoique instrumentale, de la société de tenir un registre des jours ouvrables afin de garantir la santé et la sécurité des travailleurs.

\section{Mots clés}

Directive sur le temps de travail; droit social fondamental des travailleurs à une durée maximale de travail; obligation de l'employeur d'enregistrer le temps de travail. 


\section{SUMARIO}

I. INTRODUCCIÓN: DEL CASO BANKIA AL DE DEUTSCHE BANK. II. ANTECEDENTES JURISPRUDENCIALES Y NORMATIVOS ESPAÑOLES. III. LA CUESTIÓN PREJUDICIAL, LA NORMATIVA APLICABLE Y LAS CONCLUSIONES FAVORABLES DEL ABOGADO GENERAL. IV. LA SENTENCIA: CONFIRMACIÓN DE LA NECESIDAD DE LA LLEVANZA DE UN REGISTRO DE LA JORNADA DIARIA REALIZADA. V. LA PROYECCIÓN AL DERECHO ESPAÑOL DE LA SENTENCIA. EL RDL 8/2019, DE 8 DE MARZO, COMO RESPUESTA A LAS CONCLUSIONES DEL ABOGADO GENERAL: LA COMPLEJIDAD DE UNA SIMPLEZA. VI. CUESTIONES DE INTERÉS EXTRAÍBLES DE LA SENTENCIA DE GRAN SALA EN EL CASO CCOO/DEUTSCHE BANK. BiBLIOGRAFíA.

\section{INTRODUCCIÓN: DEL CASO BANKIA AL DE DEUTSCHE BANK}

De enorme importancia es la STJUE, dictada en Gran Sala, de 14 de mayo de 2019 en el asunto C-55/18, Federación de Servicios de Comisiones Obreras/ Deutsche Bank ${ }^{2}$, que considera contraria al derecho de la unión la regulación española en la que no se contempla expresamente la obligación empresarial de llevar un registro de la jornada diaria. No solo por el hecho de dictarse escasos días después de entrar en vigor el Real Decreto Ley 8/2019, de 8 de marzo, de medidas urgentes de protección social y de lucha contra la precariedad laboral en la jornada de trabajo ${ }^{3}$, que impone expresamente en nuestro ordenamiento jurídico dicha obligación, legitimando la muy criticada opción legislativa nacional, sino, y sobre todo, por su impacto en el avance en la efectividad de la Carta de Derechos Fundamentales en las relaciones entre privados.

No se puede entender la relevancia del pronunciamiento europeo sin tener en cuenta lo acaecido en España un escaso año antes cuando la Sala Cuarta del Tribunal Supremo (en adelante, TS), en su decisiva sentencia de 23 de marzo de 2017, rec. 81/2016 país las empresas no estaban obligadas a llevar un registro de la jornada diaria

\footnotetext{
$2 \quad$ EU:C:2019:402.

3 BOE-A-2019-3481; disponible en: https://bit.ly/2Pvq7QZ.

4 ES:TS:2017:1275. Una crítica a la misma puede verse en Preciado Domenech (2017).
} 
de cada trabajador para comprobar el cumplimiento de la jornada laboral y de los horarios pactados, por entender que dicha obligación de registro solo se establece de modo expreso en determinados supuestos (como el previsto para la llevanza de las horas extraordinarias, en los contratos a tiempo parcial y en algunas jornadas especiales), pero no así respecto a la jornada ordinaria, casando con ello la interpretación contraria mantenida por la Sala de lo Social de la Audiencia Nacional ${ }^{5}$ partidaria de una interpretación teleológica de los preceptos aplicables y de considerar que la implantación de un registro diario de la jornada constituye el "presupuesto constitutivo" para controlar el exceso de jornada (el cómputo de las posibles horas extraordinarias). El denominado caso Bankia que allí se dirimía liberaba a esta entidad de la obligación de llevanza del sistema de registro de la jornada diaria efectiva de su plantilla solicitada por los sindicatos demandantes. No obstante, los tres votos particulares que acompañaban a la sentencia de la Sala de lo Social del TS insistían en la necesidad de realizar una interpretación global del ordenamiento español a la luz del ordenamiento europeo que no perdiera de vista la vinculación de la jornada con la protección de la salud laboral del trabajador. El TS confirmaría su posición mayoritaria más tarde en el caso $\mathrm{Abanca}^{6}$, reiterando que el único registro que debe llevarse es el de las horas extraordinarias realizadas, habida cuenta de que el art. 35.5 del Texto Refundido del Estatuto de los Trabajadores $^{7}$ (en adelante TRET) exclusivamente se refiere a dichas horas, y si el legislador hubiera querido que el registro se extendiera a la jornada diaria así lo hubiera indicado expresamente, del mismo modo que lo hace en relación con los trabajadores a tiempo parcial.

No es casualidad, por ello, que sea la propia Sala de lo Social de la Audiencia Nacional la que interponga una cuestión prejudicial ante el TJUE sobre la

5 Sentencia de 4 de diciembre de 2015, rec. 301/2015, ES:AN:2015:4313. Sentencia que llevó a la doctrina a afirmar que el nuevo criterio de la Audiencia Nacional, que suponía transformar lo que hasta entonces venía siendo una prerrogativa empresarial en una obligación, había llegado para quedarse (Arias, 2016; Lousada Arochena, 2016; Trujillo, 2016), si bien con fuertes dudas sobre la posibilidad de que la inexistencia de registro pudiera calificarse de infracción administrativa grave, a falta de una expresa tipificación legal (Goerlich Peset, 2017). Poniendo de relieve la deriva sancionadora provocada por la sentencia de la Audiencia nacional posteriormente casada por el Tribunal Supremo y diferenciando los supuestos posibles de infracción: Tolosa Tribiño (2017).

6 Sentencia de 20 de abril de 2017, rec. 116/2016, ES:TS:2017:1748.

7 Texto Refundido de la Ley del Estatuto de los Trabajadores, aprobado por el Real Decreto Legislativo 2/2015, de 23 de octubre (BOE-A-2015-11430). Disponible en: https://bit.ly/31WRtlD. 
exigencia o no de esta obligación en la primera ocasión que se le presenta tras ver casadas sus sentencias. Y la interpondrá también al hilo de un procedimiento de conflicto colectivo, en el que, de nuevo, el mismo conjunto de sindicatos solicitaban la misma condena (declaración de la obligación empresarial de llevar un registro diario de la jornada ordinaria), pero en relación con otra entidad bancaria: el Deutsche Bank. Su posición se verá finalmente ratificada mediante la STJUE ahora objeto de comentario. Conviene, no obstante, comenzar antes por situar el contexto en el que dicha cuestión se presenta y resuelve.

\section{ANTECEDENTES JURISPRUDENCIALES Y NORMATIVOS ESPAÑOLES}

La posición mayoritaria de la Sala de lo Social del TS, ciertamente, encontraba fundamento jurídico en la propia normativa española, pero también en la europea, aunque la lectura de ambas se realizara desde una visión excesivamente formal, literal y reductiva. Básicamente, los argumentos del Alto Tribunal para negar la obligación formal de las empresas de realizar un registro diario de la jornada laboral fueron los siguientes:

a) Interpretación literal, sistemática y teleológica del precepto. El art. 35 TRET, bajo la rúbrica de horas extraordinarias señalando en su apdo. 5 que "a efectos del cómputo de horas extraordinarias, la jornada de cada trabajador se registrará día a día y se totalizará en el periodo fijado para el abono de las retribuciones, entregando copia del resumen al trabajador en el recibo correspondiente» (el destacado es propio). Para el TS la obligación del empresario de registrar o anotar, literalmente, solo se extiende a las horas extraordinarias realizadas. Interpretación esta que, a su juicio, «se acompasa con los antecedentes históricos y legislativos que nunca impusieron una obligación del tipo que nos ocupa", como demuestra la anterior redacción del TRET y la ausencia de toda referencia a este asunto en las reformas de 2012 de dicho texto normativo. El hecho de que, por el contrario, la obligación de llevar un registro se contemple expresamente en supuestos como el contrato a tiempo parcial (art. 12.4.c TRET) y en relación con ciertos trabajadores sometidos a jornadas especiales, como en el caso de los trabajadores móviles, de la marina mercante y los trabajadores ferroviarios ${ }^{8}$, demostraría que cuando el legislador quiere un registro de toda la jornada laboral, así lo prevé, no teniendo sentido

8 Art. 10-bis-5 y art. 18-bis-2 del Real Decreto 1561/1995, de 21 de septiembre, sobre jornadas especiales de trabajo (BOE-A-1995-21346). Su texto puede encontrarse en: https://bit.ly/31TjSsG. 
reiterarlo en supuestos especiales si lo hubiera querido con carácter general, en cuyo caso, además, lo habría implantado con tal carácter en el art. 34 del TRET, que es donde se regula la jornada ordinaria. Por lo demás, para el TS, la negativa a aceptar que existe una obligación legal de llevar un registro de la jornada ordinaria diaria de los trabajadores se apoyaría también en el elemento teleológico del art. 35.5 ET, en tanto tiene como finalidad el control de la realización de horas extraordinarias y evitar excesos con los que se sobrepasen los límites que establece, pero no así para implantar un control de la jornada ordinaria.

b) Refuerza la posición del TS su jurisprudencia previa donde, en relación con el deber de informar mensualmente a los representantes de las horas extraordinarias realizadas y de facilitar copia de los resúmenes contenidos en el art. 35.5 TRET, ya había declarado que dichas obligaciones empresariales constituían un deber legal, pero que, sin embargo y en ausencia de un pacto específico al respecto, no existía en nuestro ordenamiento una obligación legal de llevar un registro para el control de la jornada ordinaria diaria.

c) Para el TS, además, nuestra normativa sería conforme con las obligaciones derivadas de la normativa de la UE. Recuerda el Tribunal que el art. 6 de la Directiva 93/104/CE relativa a determinados aspectos de la ordenación del tiempo de trabajo9, que prescribe la necesidad de limitar la duración de la jornada máxima por medio de disposiciones legales, reglamentarias o convenios colectivos estableciendo un límite máximo de cuarenta y ocho horas a la semana, incluidas las horas extraordinarias, por cada periodo de siete días, no prevé un registro obligatorio, y que en su art. 18.1.b) permite, incluso, que los Estados miembros inapliquen la jornada máxima establecida, si bien requiriendo que el trabajador preste su consentimiento, del que se informará a la autoridad competente y obligando, en tal caso, a que «el empresario lleve registros actualizados de todos los trabajadores que realicen un trabajo de este tipo». Tenor literal del que se derivaría que la obligación de llevar registros actualizados únicamente se impone en los casos que no se aplican las limitaciones del art. 6 sobre la duración de la jornada. Disposición reiterada por el art. 22 de la vigente Directiva 2003/88, relativa a determinados aspectos de la ordenación del tiempo de trabajo ${ }^{10}$.

9 Directiva 93/104/CE del Consejo, de 23 de noviembre de 1993, relativa a determinados aspectos de la ordenación del tiempo de trabajo (DO L 307, de 13 de diciembre de 1993, pp. 0018-0024).

10 Directiva 2003/88 del Parlamento Europeo y del Consejo, de 4 de noviembre de 2003, relativa a determinados aspectos de la ordenación del tiempo de trabajo (DO 
Por contra, el hecho de que la normativa comunitaria sí imponga la necesidad de llevar un registro de las horas de trabajo y de descanso en supuestos especiales como en el transporte de navegación, la navegación aérea, el trabajo en el mar, el transporte por carretera ${ }^{11}$ y otras disposiciones similares sobre jornadas especiales que han sido traspuestas a nuestras disposiciones legales y reglamentarias probaría que, en paralelo con la española, la normativa europea impone la necesidad de llevar un registro de las jornadas especiales, pero no así de la jornada ordinaria cuando no se sobrepasa la jornada máxima.

d) Finalmente, para la Sala de lo Social del TS, entender que en nuestro ordenamiento no existe un deber legal de llevar un registro diario de la jornada no dejaría indefenso al trabajador a la hora de probar la realización de horas extraordinarias, al disponer de otros medios de prueba que prueben la superación de la jornada ordinaria.

e) Aunque de modo accesorio, para reforzar su criterio mayoritario, el TS también alude a otra serie de argumentos para rechazar la declaración de la obligación pretendida, tales como que la separación de poderes que le impide usurpar el papel del legislador; la complejidad de supuestos y la dificultad de medición de las horas de trabajo efectivo en muchos de ellos; la repercusión que la creación de registro de datos tiene en la normativa de protección de

L 299, de 18 de noviembre de 2003, p. 9-19). En adelante, la referencia se hará a la DIRECTIVA 2003/88.

11 Contemplados en las siguientes directivas: Directiva 2014/112/UE, del Consejo, de 19 de diciembre de 2014, por la que se aplica el Acuerdo europeo sobre determinados aspectos de la ordenación del tiempo de trabajo en el transporte de navegación interior celebrado por la Unión Europea de Navegación Fluvial (EBU), la Organización Europea de Patrones de Barco (ESO) y la Federación Europea de Trabajadores del Transporte (ETF) (DO 367, de 23 de diciembre de 2014, pp. 86-95); Directiva 2000/79/CE del Consejo, de 27 de noviembre de 2000, relativa a la aplicación del Acuerdo europeo sobre la ordenación del tiempo de trabajo del personal de vuelo en la aviación civil celebrado por la Association of European Airlines (AEA), la European Transport Workers'Federation (ETF), la European Cockpit Association (ECA), la European Regions Airline Association (ERA) y la International Air Carrier Association (IACA) (DO L 302, de 1 de diciembre de 2000, pp. 57-60); la Directiva 1999/63/ CE del Consejo, de 21 de junio de 1999, relativa al Acuerdo sobre la ordenación del tiempo de trabajo de la gente de mar suscrito por la Asociación de Armadores de la Comunidad Europea (ECSA) y la Federación de Sindicatos del Transporte de la Unión Europea (FST) (DO 167, de 2 de julio de 1999, p. 33-37); Directiva 2002/15/ CE del Parlamento Europeo y del Consejo, de 11 de marzo de 2002, relativa a la ordenación del tiempo de trabajo de las personas que realizan actividades móviles de transporte por carretera (DO L 80, de 23 de marzo de 2002, p. 35-37). 
datos ${ }^{12}$; la limitación que ello supondría del derecho a la libertad de empresa; o el hecho de que la normativa sancionadora no contemple como infracción sancionable, de forma evidente y terminante, la falta de llevanza o incorrecta llevanza del registro.

No carente de motivación jurídica, pero consciente de las consecuencias de su pronunciamiento a la vista de la normativa vigente, la Sala Cuarta del TS hace una llamada de lege ferenda al legislador poniendo de relieve la oportunidad de una futura reforma legislativa que clarifique la obligación de llevar un registro horario y facilite al trabajador la prueba de la realización de horas extraordinarias ${ }^{13}$.

La sentencia cuenta con tres votos particulares, firmados por cinco de los trece magistrados que la suscriben, partidarios de desestimar el recurso de Bankia y de confirmar el fallo de la Audiencia Nacional favorable a en-

12 «Además, no se deben olvidar las normas reguladoras de la protección de datos, de creación de archivos de datos, y del control de estos que deberán ser tratados con respeto de lo dispuesto en la Ley 15/1999, de diciembre, y en el nuevo Reglamento 2016/679 del Parlamento Europeo y del Consejo, de 27 de abril de 2016, norma que, aunque no será de aplicación hasta el 25 de mayo de 2018, deberá tenerse en cuenta para orientar la creación de registros de datos, dado que al efecto se requiere una norma legal o pactada que "establezca garantías adecuadas del respeto de los derechos fundamentales y de los intereses del interesado" (artículo 9-2 del Reglamento citado) y es que la creación de este registro implica un aumento del control empresarial de la prestación de servicios y un tratamiento de los datos obtenidos, máxime en los supuestos de jornada flexible, de trabajo en la calle o en casa, que pueden suponer una injerencia indebida de la empresa en la intimidad y libertad del trabajador, así como en otros derechos fundamentales que tutela nuestra Constitución, especialmente en su artículo 18-4, máxime cuando la pretensión ejercitada y, el fallo que la estima v más allá del simple control de entrada y salida, por cuánto requiere almacenar datos que permitan comprobar el adecuado cumplimiento de los horarios pactados, objetivo cuyo logro requiere, incluso, un tratamiento anual de los datos recogidos para determinar el cumplimiento de la jornada anual».

13 El Supremo admite que "convendría una reforma legislativa que clarificara la obligación de llevar un registro horario y facilitara al trabajador la prueba de la realización de horas extraordinarias», pero «esa obligación no existe por ahora y los Tribunales no pueden suplir al legislador imponiendo a la empresa el establecimiento de un complicado sistema de control horario, mediante una condena genérica, que obligará, necesariamente, a negociar con los sindicatos el sistema a implantar, por cuanto, no se trata, simplemente, de registrar la entrada y salida, sino el desarrollo de la jornada efectiva de trabajo con las múltiples variantes que supone la existencia de distintas jornadas, el trabajo fuera del centro de trabajo y, en su caso, la distribución irregular de la jornada a lo largo del año, cuando se pacte». 
tender que es obligatorio llevar un registro de la jornada ordinaria de trabajo. Muchos de sus argumentos tendrán luego su reflejo en la STJUE del asunto Deutsche Bank, objeto del presente comentario.

\section{LA CUESTIÓN PREJUDICIAL, LA NORMATIVA APLICABLE Y LAS CONCLUSIONES FAVORABLES DEL ABOGADO GENERAL}

Casada la sentencia de la Audiencia Nacional ${ }^{14}$, que condenaba a la empresa Bankia al registro diario de la jornada, va a ser la misma Audiencia la que va a plantear la conformidad, o no, de nuestro sistema jurídico (interpretado de modo restrictivo por la jurisprudencial del TS) con la normativa de la Unión Europea. En concreto, mediante auto de 19 de enero de $2018^{15}$, en el marco, de nuevo, de un conflicto colectivo en el que los sindicatos legitimados solicitaban que se dictase sentencia en la que

se declare la obligación de la empresa demandada de establecer un sistema de registro de la jornada diaria efectiva que realiza la plantilla del Deutsche Bank, que permita comprobar el adecuado cumplimiento de los horarios pactados, tanto en el convenio sectorial como en los pactos de empresa que sean de aplicación y de dar traslado a la representación legal de los trabajadores, de la información sobre las horas extraordinarias realizadas, en cómputo mensual, de acuerdo con lo previsto en el artículo 35.5 del Estatuto de los Trabajadores y en la Disposición Adicional Tercera del Real Decreto 1561/1995 de 21 de septiembre sobre jornadas especiales de trabajo.

Y en la que se interesaba que, «con carácter previo, se formulase cuestión prejudicial al TJUE».

Atendiendo a esta última petición, tres son las cuestiones prejudiciales planteadas por la Audiencia Nacional al TJUE. No obstante, el abogado general (en adelante, $A G$ ) y, más tarde, el propio TJUE, las reconducirán a una única consistente en verificar

si los artículos 3, 5, 6, 16 y 22 de la Directiva 2003/88, de 4 de noviembre de 2003, relativa a determinados aspectos de la ordenación del tiempo de trabajo, en relación con los artículos 4, apartado 1, 11, apartado 3, y 16, apartado 3, de la Directiva

14 Sobre su contenido, contexto y el efecto detonante que tuvo para que la Inspección de Trabajo cambiara el criterio aplicativo que venía utilizando, véanse Lousada Arochena (2016) y Moll Noguera (2016).

15 Puede consultarse el auto en https://bit.ly/2qQzYGD. 
89/391, de 12 de junio de 1989, relativa a la aplicación de medidas para promover la mejora de la seguridad y de la salud de los trabajadores en el trabajo, y con el artículo 31, apartado 2, de la Carta, deben interpretarse en el sentido de que se oponen a una normativa de un Estado miembro que, según la interpretación de esa normativa adoptada por la jurisprudencia nacional, no impone a los empresarios la obligación de establecer un sistema que permita computar la jornada laboral diaria realizada por cada trabajador.

Varios preceptos sirven de marco jurídico para la resolución de la cuestión prejudicial. En primer lugar, del derecho de la unión, el art. 31.2 de la Carta de Derechos Fundamentales de la UE que, titulado «condiciones de trabajo justas y equitativas» declara que todo trabajador tiene derecho a trabajar en condiciones que respeten su «salud, seguridad y dignidad» (art. 31.1 CDFUE) y «tiene derecho a la limitación de la duración máxima del trabajo y a períodos de descanso diarios y semanales, así como a un período de vacaciones anuales retribuidas» (art. 31.2 CDFUE). Pero, del mismo modo, son objeto de interpretación el art. 6 de la Directiva 2003/88, de 4 de noviembre, relativa a determinados aspectos de la ordenación del tiempo de trabajo sobre «duración máxima del tiempo de trabajo semanal»" ${ }^{16}$ así como su art. 22.1, sobre condiciones para la no aplicación del mencionado art. $6^{17}$.

Ya en relación con el derecho español, los preceptos clave son el art. 34 del TRET ${ }^{18}$, titulado "Jornada», que señala, en lo que ahora interesa, el

16 Que establece que «los Estados miembros adoptarán las medidas necesarias para que, en función de las necesidades de protección de la seguridad y de la salud de los trabajadores: a) se limite la duración del tiempo de trabajo semanal por medio de disposiciones legales, reglamentarias o administrativas o de convenios colectivos o acuerdos celebrados entre interlocutores sociales; b) la duración media del trabajo no exceda de 48 horas, incluidas las horas extraordinarias, por cada período de siete días».

17 Donde se señala que: «Siempre que respete los principios generales de protección de la seguridad y la salud de los trabajadores, un Estado miembro podrá no aplicar el artículo 6 , a condición de que adopte las medidas necesarias para garantizar que: a) ningún empresario solicite a un trabajador que trabaje más de 48 horas en el transcurso de un período de siete días, calculado como promedio del período de referencia que se menciona en la letra b) del artículo 16, salvo que haya obtenido el consentimiento del trabajador para efectuar dicho trabajo; [...] c) el empresario lleve registros actualizados de todos los trabajadores que efectúen un trabajo de este tipo; d) los registros mencionados se pongan a disposición de las autoridades competentes, que podrán prohibir o restringir, por razones de seguridad y/o de salud de los trabajadores, la posibilidad de sobrepasar la duración máxima del tiempo de trabajo semanal».

18 «1. La duración de la jornada de trabajo será la pactada en los convenios colectivos o contratos de trabajo. La duración máxima de la jornada ordinaria de trabajo será de 
máximo de la jornada ordinaria de trabajo efectivo de promedio en cómputo anual y los descansos entre jornadas. Y el art. 35 TRET, titulado «Horas extraordinarias", que dispone:

1. Tendrán la consideración de horas extraordinarias aquellas horas de trabajo que se realicen sobre la duración máxima de la jornada ordinaria de trabajo, fijada de acuerdo con el artículo anterior. [...] 5. A efectos del cómputo de horas extraordinarias, la jornada de cada trabajador se registrará día a día y se totalizará en el período fijado para el abono de las retribuciones, entregando copia del resumen al trabajador en el recibo correspondiente ${ }^{19}$.

Sobre esta base jurídica, las posiciones interpretativas existentes divergen no solo en el ámbito nacional, como se ha dicho, sino también en el marco de la cuestión prejudicial. Así, de un lado, mientras que el banco y algunos Estados miembros intervinientes, consideran que el derecho de la unión europea (en adelante, DUE) no impone una obligación general a las empresas de cómputo del tiempo de trabajo, para los sindicatos demandantes, el órgano judicial remitente y la propia Comisión, tal obligación, aunque instrumental, se impone claramente, oponiéndose por ello el derecho español a la normativa europea.

Es esta segunda posición la acogida igualmente por el abogado general Pitruzzella en el caso objeto de comentario ${ }^{20}$, a partir del análisis de los objetivos de la Directiva 2003/88, la necesidad de garantizar su efecto útil y de proteger los derechos del trabajador en el cómputo del tiempo de trabajo.

En efecto, para el AG, en primer lugar, la Directiva 2003/88 tiene como objetivo el establecimiento de disposiciones mínimas destinadas a mejorar la protección y la salud en los lugares de trabajo a través de la aproximación de las normas nacionales relativas al tiempo de trabajo, estableciendo máximos de jornada y mínimos de descanso. Ello conecta con el art. 31.1 de la Carta, derecho conectado, a su vez, con la dignidad humana (estableciendo, de este modo, puentes entre el capítulo de solidaridad y el de dignidad, lo que es des-

cuarenta horas semanales de trabajo efectivo de promedio en cómputo anual. [...] 3. Entre el final de una jornada y el comienzo de la siguiente mediarán, como mínimo, doce horas. El número de horas ordinarias de trabajo efectivo no podrá ser superior a nueve diarias, salvo que por convenio colectivo o, en su defecto, acuerdo entre la empresa y los representantes de los trabajadores, se establezca otra distribución del tiempo de trabajo diario, respetando en todo caso el descanso entre jornadas».

19 El destacado es propio.

20 Conclusiones del abogado general Sr. Giovanni Pitruzzella, presentadas el 31 de enero de 2019, en el asunto C-55/18, EU:C:2019:87. 
tacable para enfatizar que se trata de un derecho y no de un principio). Afirma igualmente que, en este marco, el TJUE ha afirmado que «las disposiciones de la Directiva 2003/88 constituyen normas de Derecho Social de la Unión de especial importancia de las que debe disfrutar todo trabajador». Afirmación muy interesante pues amplía, englobando a todas las disposiciones de la directiva, ese peculiar carácter de «principio de especial importancia en el Derecho social», como peculiar expresión y categoría utilizada por el TJUE, más allá del derecho de vacaciones anual retribuido contenido en dicha directiva y para el que el TJUE ya ha reconocido, finalmente y tras muchas dudas, su carácter de derecho fundamental de eficacia horizontal. Como ocurriera en materia de vacaciones, en este caso también el AG recuerda la posición reciente del TJUE (asunto Max Planck) destacando la asimetría existente en la relación laboral y la debilidad de la posición del trabajador, de modo que, para permitir un disfrute pleno de los derechos reconocidos en la directiva, se debe eliminar todo obstáculo que los pueda menoscabar y considerar incompatible con las finalidades de la directiva toda acción u omisión de un empresario que tenga un efecto potencialmente disuasorio de su ejercicio. Sobre dicha base, aborda el contenido de las obligaciones de la Directiva 2003/88 señalando que todos los artículos que contienen disposiciones mínimas en materia de limitación del tiempo de trabajo (arts. 3 a 6) comienzan prescribiendo que los «Estados miembros adoptarán las medidas necesarias para que...», lo que, a juicio del $A G$, indica que debe quedar asegurada la eficacia de la totalidad de los derechos conferidos a los trabajadores, lo que necesariamente implica la obligación para los Estados miembros de garantizar el respeto de cada una de las disposiciones mínimas establecidas en la directiva a fin de garantizar su efecto útil. Para el AG ello, en el marco de la Directiva 2003/88, «se corresponde con la responsabilidad particular del empresario que, a su vez, tiene la obligación de adoptar las medidas adecuadas para permitir que los trabajadores ejerzan sin obstáculos los Derechos que les garantiza esta Directiva» (apdo. 55). En este contexto, considera que la inexistencia de un sistema de registro de la duración del horario de la jornada laboral vacía de efecto útil los derechos reconocidos por la directiva por varias razones:

a) Porque sin dicho sistema no existe garantía de que sean efectivamente respetados los límites temporales impuestos por la directiva, imposibilitando la distinción fiable entre horas ordinarias y extraordinarias de trabajo.

b) Porque la falta de garantías de una protección eficaz de los derechos de observancia del tiempo de trabajo no puede ser suplida por la Inspección de Trabajo, a quien se le priva de la posibilidad de control (como ha reconocido la Inspección en varios informes que el AG utiliza), impidiéndose el cumplimiento de la sentencia Worten donde ya el TJUE reconocía que la obligación del empleador de proporcionar a la autoridad competente el «acceso inmedia- 
to al registro de tiempo de trabajo puede resultar necesaria si contribuye a una aplicación más eficaz de la normativa en materia de condiciones de trabajo», lo que deviene imposible si no existe siquiera un registro.

c) Porque la inexistencia de registro supone una carga más gravosa para el trabajador a la hora de demostrar judicialmente el incumplimiento de las obligaciones de la directiva, privándolo de un elemento probatorio esencial, con independencia de que pueda demostrarlo por otras vías mucho más débiles (como la testifical de compañeros vinculados al mismo empresario que pudieran encontrarse disuadidos por tal motivo) ya que, en todo caso, "disminuye considerablemente la eficacia de los derechos garantizados» por la directiva.

d) Porque su ausencia merma significativamente también el derecho de información y de control de los representantes de los trabajadores.

Junto a ello, por otro lado, de especial relevancia es también el reconocimiento expreso por parte del AG de que la obligación de registro no está contemplada expresamente en la directiva en tanto, en este punto, el paralelismo de la normativa europea y la española resultaría evidente. Pero afirma que se trata de «una obligación de carácter instrumental, esencial, para el logro de los objetivos de la Directiva y para el ejercicio de los derechos subjetivos reconocidos en ella» (punto 7) y que la vinculación de esta obligación con los objetivos y la necesidad de dotar efecto útil a la directiva no se ve contradicha por los argumentos utilizados por algunas de las partes que han intervenido en el proceso (y que, básicamente, coinciden con la tesis opuesta mantenida por nuestro Tribunal Supremo). Y ello por los siguientes motivos:

a) Porque la interpretación literal de la norma se ve contradicha por una sistemática y teleológica de la directiva que pone de manifiesto su necesidad para garantizar el efecto útil de sus disposiciones, sin que el hecho de que en determinados casos especiales se establezca una obligación expresa de registro del tiempo de trabajo obste a tal conclusión, en tanto se trata de sectores necesitados de una protección especial (como los de tiempo parcial o trabajadores móviles) para los que el DUE prevé sistemas de control particularmente rigurosos, mientras que en el caso de los trabajadores ordinarios, la Directiva 2003/88 "presupone la existencia de un sistema de registro de tiempo de trabajo que puede consistir en una simple anotación en papel o soporte electrónico o cualquier otro medio que sirva a tal fin» (punto 77).

b) Porque la normativa europea de protección de datos personales no se opone a una normativa nacional que establezca la obligación de poner a disposición de la autoridad nacional competente ese registro para la supervisión de las condiciones de trabajo a fin de que puedan acceder a él de forma inmediata (asunto Worten) quienes tengan interés cualificado y sobre la base de que el empresario debe hacer un uso legítimo de los datos disponibles en el registro. 
c) Porque la reducción del número máximo de horas semanales de trabajo, que se alega como norma de favor del derecho español, resulta un argumento que confunde entre obligaciones sustantivas e instrumentales (de control del cumplimiento de las primeras) y ajeno al proceso, ya que no se discute la correcta transposición de las obligaciones expresamente impuestas a los Estados miembros por la Directiva 2003/88, sino el hecho de que para el correcto cumplimiento de tales obligaciones sea o no necesario establecer, además, un instrumento de control adecuado.

d) Porque la libertad de empresa reconocida en el DUE no es absoluta y el considerando 4 de la directiva expresamente establece que «la mejora de la seguridad, de la higiene y de la salud de los trabajadores en el trabajo representa un objetivo que no puede subordinarse a consideraciones de carácter puramente económico» y, además, no se indica qué obstáculos generaría la adopción de un sistema de control del tiempo de trabajo en la empresa, existiendo un amplio margen de los Estados miembros al adoptar el sistema o el establecimiento de sistemas diferenciados en función de la complejidad de la organización y de las características de cada empresa, aunque, en todo caso, el elegido debe ser adecuado para garantizar el efecto útil y la efectividad de los derechos que la Directiva 2003/88 reconoce a las personas trabajadoras.

Por todo ello, considera incompatible con el DUE una normativa nacional que no impone a las empresas la obligación de introducir un sistema de registro de jornada laboral efectuada por todos los trabajadores. A partir de ahí, el AG recuerda el deber de interpretación conforme, incluso en contra de la jurisprudencia que se opone al efecto útil de la directiva y, en caso de imposibilidad interpretativa y que resultara contra legem, al no poder aplicarse la directiva a las relaciones horizontales entre particulares, el AG declara que es de aplicación directa el art. 31.2 CDFUE. Esta es, sin duda, una afirmación importante, por cuanto hasta el momento la eficacia directa se ha afirmado en relación con el derecho a las vacaciones anuales retribuidas (asunto Bauer y Brobohn) también dentro del mismo precepto fundamental, y para el AG el derecho a la limitación de la jornada presenta la misma estructura, la misma finalidad y se encuentra en el mismo precepto constitucional, por lo que tal carácter también le debe ser predicable. $\mathrm{Y}$ «el contenido de los derechos a la limitación de la duración máxima del trabajo y a períodos de descanso de los trabajadores garantizados por el artículo 31, apartado 2, de la Carta y de las correspondientes obligaciones del empresario también comprende la adopción de un sistema de cómputo del tiempo de trabajo», pues al tratarse «de "derechos sociales" forma parte de su naturaleza la pretensión del titular a obtener prestaciones positivas del Estado o de otros sujetos obligados» y "este tipo de derechos solo se puede garantizar mediante prestaciones positivas del 
sujeto obligado, de modo que, en el caso de que estas no existan o sean insuficientes, se privará de efectividad a tales derechos» (puntos 96-97).

\section{LA SENTENCIA: CONFIRMACIÓN DE LA NECESIDAD DE LA LLEVANZA DE UN REGISTRO DE LA JORNADA DIARIA REALIZADA}

La Sentencia del TJUE, dictada en Gran Sala, de 14 de mayo de 2019, C-55/18, CCOO, acoge las tesis del abogado general. Siguiendo su estructura habitual, el Tribunal expone el marco jurídico aplicable, el contexto en el que surge el litigio principal, los argumentos del órgano del que provienen las cuestiones prejudiciales y precisa que, como hiciera el $\mathrm{AG}$, todas ellas pueden reconducirse a una única consistente en determinar si el DUE aplicable debe interpretarse en el sentido de que se oponen a una normativa en la que, según la interpretación realizada por la jurisprudencia nacional, no se impone a los empresarios la obligación de establecer un sistema que permite computar la jornada laboral diaria realizada por cada trabajador.

El TJUE comienza señalando con carácter preliminar algo interesante: es «el derecho de todo trabajador a la limitación de la duración máxima del tiempo de trabajo y a períodos de descanso diario y semanal, no solo constituye una norma del Derecho social de la Unión de especial importancia, sino que también está expresamente consagrado en el artículo 31, apartado 2, de la Carta, a la que el artículo 6 TUE, apartado 1, reconoce el mismo valor jurídico que a los Tratados» (apdo. 30, el subrayado es propio). Con tal declaración, el TJUE clarifica algunas cuestiones que venían planteando dudas, como luego se dirá. Expresamente, a continuación, traerá a colación el art. 31.2 de la Carta y mantiene que este derecho fundamental se encuentra "precisado en las disposiciones de la Directiva 2003/88» y, en especial, en sus arts. 3 (descanso diario mínimo de 11 horas consecutivas en el curso de cada periodo de 24 horas), art. 5 (descanso semanal (por cada periodo de 7 días un descanso mínimo ininterrumpido de 24 horas añadidas a las 11 ya referidas) y el art. 6 (duración máxima del tiempo de trajo semanal y duración media del trabajo que no exceda de 48 horas incluidas las extraordinarias, por cada periodo de 7 días), por lo que para garantizar el mencionado derecho fundamental dichas disposiciones no pueden ser objeto de una interpretación restrictiva en perjuicio de los derechos concedidos al trabajador (apdos. 30-33).

La última puntualización que realiza el TJUE antes de proceder a responder a las cuestiones prejudiciales es la inoperancia del art. 22 de la Directiva 2003/88 en el presente supuesto, a pesar de haber sido argumentado en la segunda y la tercera cuestión prejudicial planteada. Lo cual es relevante, dado que dicho precepto permite la inaplicación del art. 6 de la directiva (duración 
máxima) siempre y cuando se preserve el objetivo de salud y seguridad del trabajador y el Estado miembro adopte las medidas necesarias para que el empresario no solicite al trabajador superar las 48 horas, "salvo consentimiento expreso del trabajador para efectuar dicho trabajo» (art. 22.1.a) y preceptuando, asimismo, que en tal caso (de existir consentimiento, se entiende) el empresario «lleve registros actualizados de todos los trabajadores que efectúen un trabajo de este tipo» (art. 22.1.c) y se pongan a disposición de las autoridades competentes dichos registros; dichas autoridades, por razones de seguridad y salud, podrán no obstante prohibir la posibilidad de sobrepasar la duración máxima (art. 22.1.d). Y la razón no es otra sino la de que el Reino de España, de acuerdo con los debates mantenidos durante la vista celebrada, «no ha hecho uso de esta facultad», por lo que decae su proyección al caso (apdos. 34-35).

Ya en relación con el fondo del asunto, recuerda el Tribunal que la directiva mencionada establece disposiciones mínimas destinadas a la armonización de las normas nacionales relativas a la duración del tiempo de trabajo a fin de promover la mejora de la seguridad y de la salud de los trabajadores, de modo que los Estados miembros deben adoptar las medidas necesarias para que todos los trabajadores disfruten de dichas prescripciones mínimas. En concreto, están obligados a

establecer un tope de cuarenta y ocho horas respecto de la duración media del trabajo semanal, quedando expresamente incluidas en este límite máximo las horas extraordinarias, límite a cuya aplicación - fuera del caso, no pertinente en el presente asunto, previsto en el artículo 22, apartado 1, de esta Directiva- no cabe, en ningún caso, establecer excepciones, ni siquiera en el supuesto de que el trabajador afectado dé su consentimiento (ap. 39).

Es decir, que corresponde a los Estados miembros impedir que se sobrepase la duración máxima del tiempo de trabajo semanal ${ }^{21}$.

Asimismo, para la sentencia, a la hora de determinar cuáles deben ser esas medidas necesarias, se otorga un gran margen de apreciación a los Estados miembros, si bien debiendo tener siempre presente el objetivo fundamental de la directiva ("garantizar una protección eficaz de las condiciones de vida y de trabajo de los trabajadores y una mejor protección de su seguridad y de su salud») y debiendo velar para que «el efecto útil de esos derechos quede completamente asegurado, haciendo que los trabajadores se beneficien efectivamente de los períodos mínimos de descanso diario y semanal y del límite

21 Con cita en la Sentencia de 14 de octubre de 2010, Fuß, C-243/09, EU:C:2010:609, apdo. 40 . 
máximo de la duración media del tiempo de trabajo semanal establecidos» (apdo. 42), de modo que, en ningún caso, las medidas adoptadas puedan «vaciar de contenido los derechos consagrados en el artículo 31, apartado 2, de la Carta y en los artículos 3, 5 y 6, letra b), de esta Directiva» (apdo. 43).

Considera también el Tribunal que, a la hora de proceder a adoptar la trasposición, todo Estado miembro debe tener en cuenta las particularidades de la relación laboral y la asimetría a ella inherente. Esta importante y clásica idea, esencial en la fundamentación del propio contrato de trabajo, asumida expresamente por el TJUE en la sentencia del asunto Pfeiffer por vez primera $^{22}$, vuelve a destacarse en el presente caso antes de proceder a reprobar el derecho español. En concreto, porque, precisamente por esta asimetría, «es necesario impedir que el empresario pueda imponerle una restricción de sus derechos» (apdo. 44), debiendo el Estado miembro tener en cuenta que es también la posición de debilidad del trabajador la que le puede disuadir «de hacer valer expresamente sus derechos frente al empresario, en particular cuando la reivindicación de estos pudiera provocar que quedara expuesto a medidas adoptadas por el empresario que redundasen en perjuicio de las condiciones de trabajo del trabajador» (apdo. 45).

A partir de estos argumentos generales, el TJUE examina si es necesario establecer un sistema que permita computar la jornada laboral diaria realizada por cada trabajador para garantizar el respeto efectivo de la duración máxima del tiempo de trabajo semanal y de los períodos mínimos de descanso diario y semanal. Parte de la premisa, como el AG, de que «sin tal sistema no es posible determinar objetivamente y de manera fiable el número de horas de trabajo efectuadas por el trabajador ni su distribución en el tiempo, como tampoco el número de horas realizadas por encima de la jornada ordinaria de trabajo que puedan considerarse horas extraordinarias» (apdo. 47), por lo que, ante su inexistencia, «resulta extremadamente difícil, cuando no imposible en la práctica, que los trabajadores logren que se respeten los derechos que les confieren el artículo 31, apartado 2, de la Carta y la Directiva 2003/88», de modo que

una normativa nacional que no establezca la obligación de utilizar un instrumento que permita determinar objetivamente y de manera fiable el número de horas de trabajo diario y semanal no puede asegurar [...] el efecto útil de los derechos que confieren el artículo 31, apartado 2, de la Carta y esta Directiva, en la medida en que priva tanto a los empresarios como a los trabajadores de la posibilidad de comprobar si se respetan tales derechos, y, por lo tanto, puede comprometer el objetivo

22 Sentencia de 5 de octubre de 2004, Pfeiffer, C-397/01 a C403/01, EU:C:2004:584, apdo. 82. 
de dicha Directiva, que consiste en garantizar una mejor protección de la seguridad y de la salud de los trabajadores (apdo. 50).

A partir de la anterior afirmación, el TJUE procede a ir descartando cada una de las alegaciones contrarias mantenidas en el nivel nacional y en la cuestión prejudicial planteada:

a) Así, en relación con el hecho de que la duración máxima del tiempo de trabajo semanal establecida por el derecho español sea más favorable para el trabajador, el TJUE considera que se trata de un argumento que carece de relevancia porque "sin un sistema que permita computar la jornada diaria efectiva, sigue resultando igualmente difícil, cuando no imposible en la práctica, que un trabajador logre que se respete efectivamente la duración máxima del tiempo de trabajo semanal, independientemente de cuál sea esa duración» (apdo. 51).

b) Por lo que se refiere a la existencia de una obligación española expresa en el art. 35 TRET de registro de las horas extraordinarias realizadas por los trabajadores que hayan prestado su consentimiento a realizarlas, porque el TJUE considera que se trata de un argumento que no atenúa la dificultad de determinar el respeto de la jornada diaria, pues no solo la calificación de una hora como extraordinaria "presupone que se conozca" y se haya computado de antemano la jornada efectiva de cada trabajador afectado, sino que, además, la obligación de llevanza de un registro de horas «extraordinarias» no atenúa las consecuencias de la inexistencia de un sistema que pueda garantizar el respeto efectivo de las normas relativas a la duración máxima del tiempo de trabajo semanal de los trabajadores cuando no hayan aceptado realizar horas extraordinarias (apdo. 52).

c) Respecto a la salvaguarda del derecho de defensa del trabajador por disponer de otros medios de prueba, considera el TJUE que, a diferencia de un «sistema de cómputo de la jornada diaria efectiva, tales medios de prueba no permiten determinar objetivamente y de manera fiable el número de horas de trabajo diario y semanal realizadas por el trabajador»; máxime teniendo en cuenta la posición de debilidad del trabajador y que los testigos serán trabajadores de la empresa reticentes a declarar contra su empresario.

d) Tampoco acepta el TJUE que la ausencia de un registro de la jornada diaria pueda compensarse con la existencia de controles por los representantes de los trabajadores y la Inspección de Trabajo así como por la posibilidad de sanción en caso de incumplimiento de la duración máxima de jornada o de los descansos. Básicamente, porque sin la existencia de un sistema que permita computar la jornada laboral diaria realizada por cada trabajador «las propias autoridades se ven privadas de un medio eficaz de obtener acceso a datos objetivos y fiables relativos a la duración del tiempo de trabajo efectivo de los trabajadores en cada empresa, 
que puede resultarles necesario para llevar a cabo su cometido de control, y, en su caso, para imponer sanciones». La necesidad de un «sistema objetivo y accesible» que permita computar la jornada laboral diaria realizada por cada trabajador, por lo demás, «es necesario para permitir que los representantes de los trabajadores que tengan una función específica en materia de protección de la seguridad y de la salud de los trabajadores y puedan solicitar del empresario que tome medidas adecuadas, así como para presentarle propuestas».

e) Por lo que se refiere a la existencia de normas específicas del DUE donde sí se establece expresamente la obligación de registro del tiempo de trabajo, la sentencia considera que ello se hace por la necesidad de protección particular de determinadas categorías de trabajadores, pero sin que ello obste a la necesidad de una "obligación similar consistente en implantar un sistema objetivo, fiable y accesible que permita computar la jornada diaria efectiva»; obligación que "se impone de manera más general para el conjunto de los trabajadores con el fin de garantizar el efecto útil de la Directiva 2003/88 y de tener en cuenta la importancia del derecho fundamental consagrado en el artículo 31.2 de la Carta».

f) Finalmente, respecto al elevado coste económico que supondría imponer dicha obligación, el TJUE señala que la eficacia de la seguridad y la salud de los trabajadores «no puede subordinarse a consideraciones de carácter puramente económico» y que, además, ninguna parte ha indicado «de manera precisa y concreta los obstáculos prácticos que podrían impedir a los empresarios implantar, con un coste razonable, un sistema que permita computar la jornada laboral diaria realizada por cada trabajador» (apdos. 66-67).

En definitiva, para el TJUE, sin un sistema que permita computar la jornada laboral diaria realizada por cada trabajador, nada garantiza que se asegure plenamente a los trabajadores el respeto efectivo del derecho a la limitación del tiempo de trabajo, al quedar el respeto al sistema «en manos del empresario» (apdo. 58). Y aunque el TJUE reconoce que la responsabilidad empresarial en el respeto de los derechos de la directiva no puede ser ilimitada, se afirma que «una normativa de un Estado miembro que, según la interpretación de esa normativa adoptada por la jurisprudencia nacional, no impone al empresario computar la jornada laboral efectiva puede vaciar de contenido los derechos consagrados» en ella y, por ello, no es conforme con el objetivo por ella perseguido. De modo que, para garantizar el efecto útil de aquellos derechos, y del derecho fundamental consagrado en el art. 31.2 de la Carta, «los Estados miembros deben imponer a los empresarios la obligación de implantar un sistema objetivo, fiable y accesible que permita computar la jornada laboral diaria realizada por cada trabajador» (apdo. 60). Esto es, define el alcance de las obligaciones positivas de los Estado miembros, a quienes corresponde, «en el ejercicio del margen de apreciación de que disponen», definir 
los criterios concretos de aplicación de tal sistema, especialmente la forma que este debe revestir, teniendo en cuenta, en su caso, las particularidades propias de cada sector de actividad de que se trate e incluso las especificidades de determinadas empresas, como su tamaño, sin perjuicio del artículo 17, apartado 1, de la Directiva 2003/88, que permite a los Estados miembros, desde el respeto de los principios generales de protección de la seguridad y de la salud de los trabajadores, establecer excepciones a lo dispuesto, en particular, en los artículos 3 a 6 de esta Directiva cuando, a causa de las características especiales de la actividad realizada, la jornada de trabajo no tenga una duración medida o establecida previamente o cuando pueda ser determinada por los propios trabajadores.

En consecuencia, y para terminar, el TJUE reitera su doctrina general en relación con las normas nacionales que se oponen a directivas del DUE, recordando que solo están vinculados los Estados a las obligaciones derivadas de las directivas y que, en caso de incumplimiento o trasposición no acorde a las mismas, los órganos judiciales (como autoridad del Estado) deben interpretar todo el sistema normativo interno a la luz de la directiva a fin de alcanzar interpretación "conforme» del derecho nacional con el DUE, lo que incluye la obligación que tienen de modificar la jurisprudencia consolidada basada en una interpretación del derecho nacional incompatible con el derecho de la UE. Por ello concluye, en Gran Sala, que:

Los artículos 3, 5 y 6 de la Directiva 2003/88 del Parlamento Europeo y del Consejo, de 4 de noviembre de 2003, relativa a determinados aspectos de la ordenación del tiempo de trabajo, interpretados a la luz del artículo 31, apartado 2, de la Carta de los Derechos Fundamentales de la Unión Europea y de los artículos 4, apartado 1, 11, apartado 3, y 16, apartado 3, de la Directiva 89/391/CEE del Consejo, de 12 de junio de 1989, relativa a la aplicación de medidas para promover la mejora de la seguridad y de la salud de los trabajadores en el trabajo, deben interpretarse en el sentido de que se oponen a una normativa de un Estado miembro que, según la interpretación de esa normativa adoptada por la jurisprudencia nacional, no impone a los empresarios la obligación de establecer un sistema que permita computar la jornada laboral diaria realizada por cada trabajador.

\section{LA PROYECCIÓN AL DERECHO ESPAÑOL DE LA SENTENCIA. EL RDL 8/2019, DE 8 DE MARZO, COMO RESPUESTA A LAS CONCLUSIONES DEL ABOGADO GENERAL: LA COMPLEJIDAD DE UNA SIMPLEZA}

El Real Decreto Ley 8/2019, de 8 de marzo, de medidas urgentes de protección social y de lucha contra la precariedad laboral en la jornada de tra- 
bajo (en adelante, RDL 8/2019) ${ }^{23}$, instaura en España una obligación legal, de carácter general, para todos los trabajadores por cuenta ajena sometidos al TRET $^{24}$, de llevar un registro de la jornada ordinaria diaria de trabajo. Sin esperar a la sentencia del TJUE, el RDL alega como sustento justificativo de la urgente necesidad para dictarlo ${ }^{25}$ las conclusiones del abogado general en el asunto C-55/18, los argumentos acogidos por este que ya anticipara la cuestión prejudicial planteada por la Audiencia Nacional, así como la realidad española puesta de manifiesto por varios informes de la Inspección de Trabajo en torno a la amplia superación en nuestro país de las jornadas máximas permitidas.

El mencionado RDL incluye reformas normativas dirigidas a regular el registro de jornada, como forma de combatir la precariedad laboral que provoca la realización de un tiempo de trabajo superior a la jornada laboral legal o convencionalmente establecida y que afecta a dos elementos esenciales de la relación laboral con repercusión en la vida personal de las personas trabajadoras, tales como el tiempo de trabajo — con afectación a la corresponsabilidad familiar - y al propio elemento salarial — con afectación en una merma de las cotizaciones a la Seguridad Social—. Tras señalar que las normas que permiten cierta flexibilidad horaria para adaptar las necesidades de la empresa a las de la producción y el mercado (distribución irregular de la jornada, jornada a turnos u horas extraordinarias), no se pueden confundir con el incumplimiento de las normas sobre jornada máxima y horas extraordinarias, la exposición de motivos del RDL 8/2019 pone de relieve los problemas en el control de la jornada por parte de la Inspección de Trabajo y Seguridad Social, las dificultades de reclamación por parte de las personas trabajadoras afectadas por la extralimitación horaria sobre las jornadas legales o convencionalmente pactadas, como consecuencia de «la ausencia en el Estatuto de los Trabajadores de una obligación clara por parte de la empresa del registro de la jornada que realizan las personas trabajadoras». Considera, en línea con la sentencia de la Audiencia Nacional, que el registro de jornada, que no de horas extraordinarias ya existente, «es el requisito constitutivo para controlar los excesos de jornada»

23 BOE-A-2019-3481, disponible en: https://bit.ly/31SHqxy.

24 Obligación no modulada por el número de trabajadores de la empresa, el carácter ordinario o especial de la relación de trabajo, el sector de actividad o la distribución flexible o irregular de la jornada, como destaca Marín Alonso (2019: 14).

25 Cuestionando que la norma cumpla los requisitos establecidos en el art. 86 de la Constitución Española y criticando que por esa supuesta urgencia se haya desaprovechado la ocasión para armar desde la ley un mecanismo cabal y coordinado sobre control del cumplimiento de las normas sobre tiempo de trabajo que atienda a todos los aspectos que aglutina este complejo asunto: Monreal (2019). 
y pone de relieve que, aunque el TS no confirmara la sentencia de la Audiencia Nacional, reclamara de lege ferenda una reforma legislativa que clarificara la obligación de llevar un registro horario y facilitara al trabajador la prueba de la realización de horas extraordinarias. Necesidad que el RDL entiende ratificada por las «conclusiones del Abogado General de 31 de enero de 2019 en el asunto C-55/18», de modo que «la creación del registro de jornada por el presente real decreto-ley asegura la conformidad de la normativa europea con el ordenamiento europeo» y sirve "para dotar de mayor efectividad a la Inspección de Trabajo».

Con tal sustento, el art. 10 del RDL 8/2019 modifica el art. 34.7 TRET a fin de permitir al Gobierno establecer en un futuro «especialidades en las obligaciones de registro de jornada, para aquellos sectores, trabajos y categorías profesionales que por sus peculiaridades así lo requieran». Asimismo, el RDL añade al mismo precepto (art. 34 TRET) el importante apdo. 9²6, en el que se declara la obligación empresarial de llevar un «registro diario de jornada» organizado y documentado de conformidad con lo que establezca la negociación colectiva, acuerdo de empresa o, supletoriamente, por decisión unilateral empresarial, así como la obligación de su conservación para poder ponerlo a disposición de los interesados. Obligación general que toda empresa deberá cumplir a partir de la entrada en vigor del RDL (12 de mayo 2019), ya que su incumplimiento se considera ahora una infracción grave ${ }^{27}$ que podrá dar lugar a las pertinentes sanciones.

26 El nuevo art. 34.9 TRET ahora declara: «La empresa garantizará el registro diario de jornada, que deberá incluir el horario concreto de inicio y finalización de la jornada de trabajo de cada persona trabajadora, sin perjuicio de la flexibilidad horaria que se establece en este artículo.

Mediante negociación colectiva o acuerdo de empresa o, en su defecto, decisión del empresario previa consulta con los representantes legales de los trabajadores en la empresa, se organizará y documentará este registro de jornada.

La empresa conservará los registros a que se refiere este precepto durante cuatro años y permanecerán a disposición de las personas trabajadoras, de sus representantes legales y de la Inspección de Trabajo y Seguridad Social».

27 El art. 11 del RDL 8/2019 modifica, asimismo, el art. 7.5 del Texto Refundido de la Ley sobre Infracciones y Sanciones en el Orden Social, aprobado por el Real Decreto Legislativo 5/2000, de 4 de agosto (BOE-A-2000-15060), a fin de adecuar la actuación de la Inspección a las nuevas exigencias empresariales, considerando ahora infracción grave de las empresas: «La transgresión de las normas y los límites legales o pactados en materia de jornada, trabajo nocturno, horas extraordinarias, horas complementarias, descansos, vacaciones, permisos, registro de jornada y, en general, el 
Tan solo un día después de la entrada en vigor de la nueva norma social (RDL 8/2019), y ante las críticas voces empresariales alzadas contra dicho deber y su imposibilidad de cumplimiento, el Ministerio de Trabajo difundía una Guía sobre registro de jornada ${ }^{28}$. Es decir, se ofrece un mecanismo de soft law no vinculante, pero imposible de ignorar en estos primeros momentos, con el que se busca apaciguar a la clase empresarial y proceder a disipar algunas dudas de un precepto que, aunque claro, resulta excesivamente abierto en algunos de sus contornos ${ }^{29}$. En dicha guía, hecha pública el 13 de mayo de 2019 y cuyo examen pormenorizado queda evidentemente al margen de esta nota, se van realizando preguntas y ofreciendo respuestas, en relación con el ámbito subjetivo de la norma, las obligaciones de registro en casos de flexibilidad horaria y distribución irregular, en los supuestos triangulares de relaciones laborales (como las empresas de trabajo temporal o en supuestos de existencia de contratas), respecto a la permanencia de la obligación de registro en supuestos de pactos de libre disponibilidad o plena disponibilidad horaria, el registro como obligación y no mera potestad del empleador, su contenido, su compatibilidad con otros registros para los que ya existía una obligación legal (tiempo parcial, jornadas especiales o trabajadores desplazados), sobre la documentación y organización del registro, o en relación con el régimen sancionador, donde, por cierto, se admite que se pueda valorar la existencia de una negociación en curso con los representantes legales de los trabajadores antes de imponer una sanción, agarre este cuya virtualidad no han dejado de aprovechar de modo inmediato las empresas para evitar la sanción.

$\mathrm{La}$ intranquilidad que ha generado la obligación de registro de la jornada diaria de trabajo y la existencia de algunos criterios técnicos anteriores de la Inspección de Trabajo no del todo compatibles con la nueva regulación ha abocado, asimismo, a la reciente publicación de un nuevo criterio de la Inspección de Trabajo: el Criterio Técnico 101/2019 sobre la actuación de la Inspección de Trabajo y Seguridad Social en materia de registro de jornada ${ }^{30}$. En él se parte de que uno de los problemas que ha tenido la Inspección para realizar sus competencias de vigilancia y control del cumplimiento de la normativa laboral en materia de jornada ha sido, precisamente, la ausencia en el Estatuto de los Trabajadores de una obligación clara por parte del empleador de proceder al registro de la jornada que realizan las personas trabajadoras. Y,

tiempo de trabajo a que se refieren los artículos 12, 23 y 34 a 38 del Estatuto de los Trabajadores».

28 Disponible en: https://bit.ly/2q1nJ9z.

29 Poniendo de manifiesto estas críticas De la Morena (2019).

30 Disponible en: https://bit.ly/32SwPUF. 
tras indicar el iter judicial habido en esta materia, resalta el apdo. 62 de la STJUE de 14 de mayo de 2019, C-55/18, donde se expresa sin ambages que «la implantación de un sistema, objetivo, fiable y accesible que permita computar la jornada laboral diaria realizada por cada trabajador forma parte de la obligación general que incumbe a los Estados miembros y a los empresarios [...] además que tal sistema es necesario para permitir que los representantes de los trabajadores que tengan una función específica en materia de protección de la seguridad y salud de los trabajadores ejerzan su derecho». Destaca, así, la obligación implícita derivada del derecho de la UE como parte integrante de la obligación de los Estados miembros y empresarios extraíble de la Directiva 2003/88.

El criterio técnico aborda varios aspectos fundamentales y casi todos ellos se fundamentan en la STJUE del asunto C-55/18 como criterio legitimador, a la par que interpretativo, del nuevo derecho nacional o en obligaciones derivadas del DUE en un sentido más amplio. Así ocurre cuando aborda la obligatoriedad del registro de jornada, como obligación de resultado del empresario y no como una mera potestad de este ${ }^{31}$; al referirse al contenido del registro de jornada, donde se insiste que debe contener, necesariamente, el inicio y el final de la jornada diaria, aunque no obligatoriamente las interrupciones o pausas que no tengan carácter de tiempo de trabajo ${ }^{32}$; cuando se declara la compatibilidad del nuevo registro de horas ordinarias con otros obligatorios ya existentes en la normativa laboral, como los del registro diario de los contratos a tiempo parcial (art. 12.4.c TRET), el registro de horas extraordinarias (art. 35.3 TRET) o los establecidos en la regulación de determinadas jornadas especiales $^{33}$; en relación con la conservación del registro de jornada, compren-

31 Donde se resalta que el carácter obligatorio y no facultativo ha sido confirmado por el TJUE para garantizar el derecho fundamental del art. 31.2 CDFUE y los derechos en materia de jornada de la Directiva 2003/38/CE que obligan a los Estados miembros a garantizar que se respetan los periodos mínimos de descanso e impiden que se sobrepase la duración máxima del tiempo de trabajo.

32 El criterio se fundamenta en la STJUE señalando que, aunque a la hora de determinar la forma de hacerlo existen muchos métodos, deberá tratarse de un sistema «objetivo y fiable, de manera que permita computar la jornada laboral diaria realizada por cada trabajador", añadiendo que deberá tratarse de un criterio ex post y no ex ante, en el sentido de que no bastará con el calendario laboral o los cuadrantes horarios elaborados para determinados periodos, sino que deben hacerse constar los registros sobre las horas efectivamente trabajadas, cuya cuantía solo se conoce una vez realizado el registro.

33 Aunque en este aspecto no se hace ninguna referencia explícita a la STJUE del asunto Deutsche Bank, lo cierto es que también el derecho de la UE se encuentra presente, 
siva de cualquier medio que permita su consulta inmediata para evitar que pueda sufrir alteraciones ${ }^{34}$; al abordar la organización y documentación del registro, que será la determinada por la negociación colectiva, acuerdo de empresa, o en su defecto decisión del empresario previa consulta con los representantes de los trabajadores, exigible en cualquier caso ${ }^{35}$; o en relación con el régimen sancionador, único aspecto donde no se menciona el DUE, para recordar el carácter de infracción grave de la transgresión de las obligaciones en materia de registro de jornada, si bien resaltando que estas no constituyen un fin en sí mismo, sino un instrumento para el control del cumplimiento de la normativa en materia de tiempo de trabajo y sus consecuencias respecto de la salud laboral, así como de la realización y el abono y cotización de las horas extraordinarias, de modo que si se cumple la normativa sobre tiempo de trabajo, pese a no llevarse el registro, tan solo se formulará un requerimiento para dar cumplimiento

cuando se señala que, precisamente, esos registros particulares en casos de jornadas especiales, como en los trabajadores móviles, trabajadores en la marina mercante y los que realizan servicios de interoperabilidad transfronteriza en el transporte ferroviario, son consecuencia del cumplimiento de las obligaciones derivadas de varias directivas europeas.

34 Tras señalar que nada dice nuestro derecho en cuanto al modo de conservación, considera que es válido cualquier medio, siempre que reúna las características generales precisadas por la STJUE del asunto C-55/18 (EU:C:2019:402), como en la STJUE del asunto C-342/12 (EU:C:2013:355), en ella mencionada, que refrendaba la obligación del empleador de permitir la consulta inmediata del registro en el centro de trabajo para evitar cualquier posibilidad de alteración de los datos en el intervalo que media entre la visita de la inspección y el control efectivo de tales datos por dichas autoridades.

35 Donde se insiste en que cualquiera que sea el sistema, debe quedar garantizada la fiabilidad y veracidad de los datos registrados, tratarse de un sistema objetivo, que garantice la no alteración posterior de los datos y que sea respetuoso con la normativa en materia de protección de datos, aludiendo expresamente a la Ley Orgánica 3/2018, de 5 de diciembre, de protección de datos personales y garantía de los derechos digitales (BOE-A-2018-16673) y al Reglamento (UE) 2016/679 del Parlamento Europeo y del Consejo, de 27 de abril de 2016, relativo a la protección de las personas físicas en lo que respecta al tratamiento de datos personales y a la libre circulación de estos datos y por el que se deroga la Directiva 95/46/CE (Reglamento general de protección de datos) (DO L 2016). En este sentido, se declara la posibilidad que tiene la inspección de tomar el original del registro como medida cautelar contemplada en la Ley Ordenadora del Sistema de Inspección de Trabajo y Seguridad Social, precisando que el control de la inspección se dirigirá no solo a verificar la existencia del registro, sino a que su forma de organización y documentación haya ido precedida del proceso de negociación o de consulta. 
a dicha obligación legal. Ausencia de referencia expresa a la STJUE en este punto que, no obstante, podría haberse realizado al constituir, en definitiva, su esencia, en tanto no cabe comprobar el cumplimiento del derecho fundamental al descanso y al límite de la jornada previsto en la Directiva 2003/88 y en el art. 31.2 CDFUE, sin la llevanza de dicho registro, ya que solo esta obligación formal permite verificar el cumplimiento de los derechos sustantivos de modo indubitado con independencia de que existan otros medios para ello.

Como puede comprobarse, la actual regulación española, llena de incógnitas y que fomenta la negociación colectiva para su complemento y realización práctica, en definitiva, obtiene el respaldo europeo con la sentencia del TJUE dictada en Gran Sala, legitimándola y poniendo de manifiesto la importancia de un sistema multinivel de tutela de derechos cada vez más consolidado y cuya apuesta por los derechos sociales, antes tan olvidado, comienza a ser una realidad tras el pilar social y la sombra cada vez más cercana del brexit.

\section{CUESTIONES DE INTERÉS EXTRAÍBLES DE LA SENTENCIA DE GRAN SALA EN EL CASO CCOO/DEUTSCHE BANK}

En el ámbito nacional, el RDL 8/2019 ha suscitado enormes reacciones e interrogantes sobre la viabilidad y eficacia de la nueva obligación de registro diario de jornada y provocado un gran debate doctrinal, en tanto se considera que resulta difícil de compaginar con sistemas tendentes a la flexibilidad, a la distribución irregular de la jornada, a la digitalización, al trabajo a distancia o bien fuera del centro de trabajo ${ }^{36}$.

A mi juicio, no obstante, todos estos nuevos sistemas de organización del tiempo de trabajo no merman la eficacia, ni la oportunidad, de la obligación de registro, ni, mucho menos, lo hacen imposible o altamente complejo. En todos los supuestos porque, junto al tiempo de trabajo efectivo, se puede pactar que consten también los tiempos de descanso y pautas que no son de trabajo efectivo. En la jornada flexible, porque basta con sistemas en los que conste el inicio y salida para comprobar que se realizan las horas pactadas; en la distribución irregular, porque es posible claramente el registro de la jornada ordinaria diaria, ya que entiendo que no hay incumplimiento de la normativa sancionable si el comportamiento de superación de la jornada máxima se analiza dentro del periodo en que es posible realizar dicha distribución irregular (que podrá variar en caso de pacto al respecto en la negociación colectiva) en tanto que es la propia ley (TRET) la que permite este sistema, y

36 En esta línea, Igartúa Miró (2019) y Marin Alonso (2019). 
debe realizarse una interpretación integradora y sistemática del mismo; en el trabajo a distancia, porque precisamente los sistemas tecnológicos permiten la distribución del horario a elección del trabajador (de tratarse de esta modalidad) o comprobar que se realiza la jornada dentro del horario pactado; en los trabajadores que prestan servicios fuera del centro, a través de mecanismos de control informático o tradicionales donde consten los tiempo s de trabajo y descanso. En general, basta con incorporar dentro del registro no solo la jornada de trabajo efectiva, sino también los descansos no retribuidos (reales o a modo de bolsa de horas) para cumplir con la obligación legal y lograr la protección de la salud del trabajador, de su vida personal y familiar, a través del control de la realización de una jornada máxima. Si antes de que se impusiera la obligación legal ya algún autor hacía una llamada al uso de las TIC, por parte de sindicatos y trabajadores, para acreditar el tiempo de trabajo extra (Preciado Domenech, 2017: 13), no cabe duda de que estos sistemas facilitarán el control efectivo de la jornada también ahora. Cuestión distinta es, sin duda, el tratamiento de los datos personales que estos sistemas pueden conllevar, incluso de datos sensibles como la actividad sindical. Pero a tal efecto puede entenderse que es la propia relación laboral o, incluso, el cumplimiento de una obligación legal, como supuestos de licitud previstos por el propio Reglamento Europeo de Protección de Datos ${ }^{37}$, el que dotaría de cobertura legal su tratamiento siempre y cuando, igualmente, se cumplan el resto de los criterios exigidos, tales como el de información, transparencia y, sobre todo, necesidad y proporcionalidad en el tratamiento. Bastaría una aplicación informática donde el trabajador pudiera cerrar o parar el sistema cuando realiza actividades de descanso o que puedan afectar a sus derechos fundamentales (privacidad, libertad religiosa, sindical, etc.) para que el sistema de registro resulte no solo efectivo, sino también proporcional.

En todo caso, al margen del análisis del derecho nacional, que escapa de este comentario, lo cierto es que desde el estricto análisis de derecho de la Unión Europea que ahora nos convoca, la sentencia en el asunto CCOO/ Deutsche Bank (C-55/18) resulta altamente relevante.

En efecto, su importancia no solo reside en haberse erigido en un instrumento incuestionable para ratificar y legitimar la normativa española proclamada antes incluso de ser dictada por la Gran Sala, sino también por presentar algunos aspectos de interés desde el punto de vista estrictamente del DUE

37 Reglamento UE 2016/679, de 27 de abril de 2016, relativo a la protección de las personas físicas en lo que respecta al tratamiento de datos personales y a la libre circulación de estos datos y por el que se deroga la Directiva 95/46/CE (DO, L 119, 4 de mayo de 2016). 
y de la eficacia de los derechos fundamentales de la CDFUE que conviene simplemente reseñar.

En primer lugar, la sentencia contribuye a perfilar algunas de las categorías utilizadas con anterioridad por el TJUE en ámbitos diversos al social. Es de sobra conocida la progresiva evolución del TJUE respecto a los derechos fundamentales antes de la existencia de una Carta de Derechos con igual valor jurídico que los Tratados y su consideración final como "principios generales del Derecho comunitario» ${ }^{38}$ (luego de la UE) cuyo contenido vendría delimitado por las tradiciones constitucionales comunes de los Estados miembros ${ }^{39}$ y los tratados internacionales sobre derechos humanos de los que son parte los Estados miembros y, en especial, el $\mathrm{CEDH}^{40}$; esto es, que los derechos fundamentales se erigen en principios generales constitucionales de la UE. Esta configuración ha permitido la aplicación directa, al ámbito de las relaciones laborales entre privados, de derechos fundamentales con independencia de que, en principio, pareciera que se regían por directivas incorrectamente traspuestas, soslayando, así, la insistida ineficacia directa de sus disposiciones a las relaciones horizontales. Conocidos son los casos Mangold ${ }^{41}$ y Kücükdevecit2 en relación con el principio de igualdad y no discriminación por razón de la edad, regulado en una directiva (inaplicable directamente a las relaciones entre particulares) y que el TJUE decidió calificar como principio general del DUE a pesar de no contenerse referencia alguna a ello en la CDFUE anterior, no encontrarse tal derecho de modo pacífico en las tradiciones constitucionales comunes, ni en los tratados internacionales ni, por ende, contenerse mención alguna en el que se supone su referente: el CEDH. Los principios generales del DUE, como derechos fundamentales de la UE, permiten, así pues, en caso de no poder hacerse una interpretación conforme con una directiva, excluir la norma nacional aplicable y la directa aplicación del principio.

Aunque es cierto que en la última sentencia mencionada ya se alude a la CDFUE, tras la entrada en vigor de la Carta de Lisboa, ya con carácter vinculante, se refuerza la eficacia horizontal de estos derechos provenientes de principios generales de rango constitucional. Y con la nueva y vigente CDFUE, el problema suscitado era ahora el de diferenciar entre "principios

38 Sentencia del Tribunal de Justicia de 12 de diciembre 1969, Stauder, C-29/69, EU:C:1969:57.

39 Sentencia del Tribunal de Justicia de 17 de diciembre de 1970, Internationale Handelsgesellschaft, C-11/70, EU:C:1970:114.

40 Convenio este al que se hará expresa mención por vez primera en Sentencia del Tribunal de Justicia de 28 de octubre de 1975, Rutili, C-36/75, EU:C:1975:137.

41 STJUE (Gran Sala) de22 de noviembre de 2005, Mangold, C-144/04, EU:C:2005:709.

42 STJUE de 19 de enero de 2010, Kücükdeveci, C-555/07, EU:C:2010:21 
generales del Derecho de la UE», «principios informadores» y resolver si, una vez asumida la Carta, los primeros (generales) pasaban a desaparecer como categoría propia al quedar absorbidos por los derechos fundamentales en ella contenidos y con los límites y esencia por ella prescritos. A mi juicio, en tanto los «principios generales» del derecho de la UE se construyen para introducir los derechos fundamentales en el ámbito de la UE (CE inicialmente), debe ya entenderse que han sido absorbidos por el concreto derecho fundamental contemplado en la Carta, es decir, se trataría de una categoría ya válida tan solo para el TJUE si quisiera integrar algún derecho futuro no contenido en la misma porque, en los ya contemplados, sería de plena aplicación la Carta de Lisboa ${ }^{43}$. De este modo, quedaría clara la diferencia entre «los principios generales», ahora claramente «derechos fundamentales», y los «otros principios» a los que alude la Carta en sus arts. 51.1 y 52.5, como antagónicos a los derechos fundamentales subjetivos que, en paralelo con el ordenamiento español, podríamos denominar "principios informadores» y cuya carencia de eficacia directa horizontal dejaría claro el TJUE en su famosa sentencia Association de médiation sociale, de 15 de enero de 2014, C-176/12.

Pero, en materia laboral, junto a los "principios generales del DUE» como categoría jurídica claramente definida, el TJUE ha utilizado otra categoría adicional. Tal es considerar ciertos derechos contenidos en directivas como principios sociales del derecho de la UE de especial importancia, o haciendo referencia a que un determinado precepto debe considerarse como una norma del derecho social de la UE de especial importancia. Categoría singular en tanto, al menos en el derecho a las vacaciones anuales retribuidas, tal consideración no dio lugar a considerarlo directamente aplicable a las relaciones entre privados, sino más bien al contrario, rechazando dicha eficacia horizontal por contenerse el derecho en una directiva ${ }^{44}$. También principios muy importantes, aunque poco eficaces, hasta los importantes y recientes asuntos resueltos por el TJUE (Gran Sala) en sentencia de 6 de noviembre de 2018, Bauer y Broßonn ${ }^{45}$, donde, por fin, se ha clarificado esta «atípica» designación jurídica para considerar, al menos en relación con el derecho a las vacaciones, que se trata de un derecho fundamental, contenido en el art. 31.2 de la Carta,

43 Sobre esta cuestión véase Nogueira Guastavino (2017: 17).

44 Claramente ello se plasma en la Sentencia de 24 de enero de 2012, Maribel Domínguez, C-282/10, EU:C:2012:33.

45 Sentencia de 6 de noviembre de 2018, Bauer y Willmeroth, C-569/16 y C-570/16, EU:C:2018:871. 
directamente aplicable en las relaciones entre particulares ${ }^{46}$. Sentencias estas relevantes no solo por la agradecida clarificación, sino, y sobre todo, por poner de manifiesto la aplicación directa horizontal de los derechos fundamentales de la Carta, incluidos algunos, como el mencionado, dentro del "fastidioso» capítulo de solidaridad, en tanto derivados también de la dignidad humana. El hecho de que tanto en vacaciones como en limitación de jornada se esté hablando de la seguridad y salud del trabajador y tal sea el objetivo perseguido refuerza dicha conexión.

Y con la reciente sentencia en el asunto Deutsche Bank, el TJUE no hace sino confirmar a qué se refería con esos principios o normas de derecho social de especial importancia, cuya determinación resultaba incierta. Deja claro que las normas de duración máxima de la jornada de trabajo contenidas en la Directiva 2003/88 y, más concretamente, los artículos relativos al descanso diario, semanal y duración máxima y media (arts. 3, 5 y 6 de la misma) constituyen normas que precisan el derecho fundamental contenido en el art. 31.2 $\mathrm{CE}$ y que "para garantizar el derecho fundamental, dichas disposiciones no pueden ser objeto de una interpretación restrictiva» (apdos. 30-33). En otras palabras, dichos principios de especial importancia, de contemplarse en la CDFUE, pasarían a ser derechos fundamentales directamente aplicables con eficacia horizontal.

Por otro lado, baste señalar que, igualmente, cabe destacar de la sentencia comentada que el TJUE declare, como una parte del derecho reconocido en la Carta y desarrollado por la directiva, la existencia de una obligación instrumental no expresamente contemplada en ninguno de esos instrumentos. Las posibilidades interpretativas que esta sentencia abren al propio Tribunal podrían, así en principio, resultar exorbitantes y tendentes a generar cierta inseguridad jurídica. Sobre todo en un ámbito como el de la UE, donde se insiste en el principio de competencia. Sin embargo, para evitar recelos, del razonamiento del propio Tribunal se pueden inferir algunas pautas que permiten considerar razonable la inclusión de una obligación ausente. En primer lugar, que la misma sea implícita, sin que, por ello, el Tribunal pueda extender su larga mano interpretativa para crear obligaciones fundamentadas en el uso alternativo del derecho; es decir, que la directiva ponga de manifiesto su necesidad o la "presuponga» para garantizar el efecto útil de sus disposiciones. Y que se trate de una obligación «esencial» para el logro de los objetivos de

46 Véase un comentario en Nogueira Guastavino (2019). De modo más general y descriptivo sobre el derecho a las vacaciones retribuidas en el DUE con un resumen de las sentencias más recientes, véase Monereo y Guindo (2019). Para un estudio de la jurisprudencia anterior, Gorelli Hernández (2015). 
la directiva y para el ejercicio de los derechos subjetivos en ella reconocidos que desarrollan el consagrado en la Carta, en este caso la determinación de periodos máximos de jornada, es decir, ordenación del tiempo de trabajo para promover la mejora de la seguridad y salud de los trabajadores. El tiempo nos dirá si el efecto útil de la directiva permite, o no, entender existentes obligaciones instrumentales en relación con directivas en las que no esté en juego un derecho fundamental expresado en la Carta.

\section{Bibliografía}

Arias Domínguez, A. (2016). Registro diario e individual de la jornada de trabajo: ¿instrumento sólo para las horas extras, o también para la distribución irregular de jornada? Comentario a la SAN 207/15, de 4 de diciembre. Revista General de Derecho del Trabajo y de la Seguridad Social, 44.

De la Morena Corrales, P. (2019). El Real Decreto-ley 8/2019, de 8 de marzo, de medidas urgentes de protección social y de lucha contra la precariedad laboral en la jornada de trabajo (en especial, la obligación de registro de jornada). Trabajo y Derecho, 54, 129-138.

Goerlich Peset, J. M. (2017). La obligatoriedad del registro de la jornada diaria a la espera del criterio del Tribunal Supremo. Trabajo y Derecho, 27, 112-118.

Gorelli Hernández, J. (2015). El impacto de la jurisprudencia comunitaria en la regulación sobre vacaciones. Revista Andaluza de Trabajo y Bienestar Social, 130, 271-310.

Igartúa Miró, M. T. (2019). La obligación de registro de la jornada de trabajo tras el RDL 8/2019. Revista Andaluza de Trabajo y Bienestar Social, 147, 115-149.

Lousada Arochena, J. F. (2016). Registro y control de la jornada de trabajo. Nueva Revista Española de Derecho del Trabajo, 192, 243-260.

Marín Alonso, I. (2019). La obligación empresarial de registro de la jornada ordinaria de trabajo ante el Derecho de la Unión Europea y el Derecho interno. Revista General de Derecho del Trabajo y de la Seguridad Social, 53.

Moll Noguera, R. (2016). Comentario a la sentencia de la Audiencia Nacional de 4 de diciembre de 2015, núm. 207/2015, ponente D. Ricardo Bodas Martín, sobre la obligatoriedad del registro de jornada del art. 35.5 ET. Revista de Información Laboral, 3, 111-126.

Monereo Pérez, J. L. y Guindo Morales, S. (2019). La nueva doctrina comunitaria sobre las vacaciones como período de descanso: el reciente acervo jurisprudencial del Tribunal de Justicia de la Unión Europea. La Ley Unión Europea, 67.

Monreal, E. (2019). Registro de la jornada: ¿Era urgente y necesario implantarlo legalmente? Diario La Ley, 9394, 3.

Nogueira Guastavino M. (2017). La Carta de Derechos fundamentales de la Unión Europea: una lectura social de sus disposiciones generales. En Balance y perspectivas de la politica laboral y social europea: XXVII Congreso Nacional de Derecho 
del Trabajo y de la Seguridad Social: Tarragona, junio de 2017 (pp. 69-239). Madrid: Editorial Cinca.

Nogueira Guastavino, M. (2019). El final de un principio y el comienzo de un derecho: las vacaciones anuales retribuidas como derecho fundamental y su repercusión en materia de responsabilidad por incumplimiento del Derecho de la Unión Europea. Revista del Ministerio de Trabajo, Migraciones y Seguridad Social, 142.

Preciado Domenech, C. H. (2017). El registro de la jornada ordinaria en la nueva doctrina del TS: comentario a la STS 23 de marzo de 2017 (RCUD 81/2016). Revista de Información Laboral, 7, 147-162.

Tolosa Tribiño, C. (2017). La reciente doctrina del Tribunal Supremo sobre registro de jornada y sus efectos sobre las actuaciones de la Inspección de Trabajo. Trabajo y Derecho, 31-32, 116-130.

Trujillo Pons, F. (2016). La relevante sentencia de la Audiencia Nacional (núm 207/2015) por la que se exige el establecimiento de un sistema de registro de la jornada diaria efectiva con objeto de comprobar el cumplimiento de los horarios pactados con los trabajadores. Nueva Revista Española de Derecho del Trabajo, 187, 277-283. 